\title{
Genetic diversity mirrors trophic ecology in coral reef fish feeding guilds
}

\section{Laura Gajdzik $^{1}$ (D) | Giacomo Bernardi ${ }^{2}$ | Gilles Lepoint ${ }^{3}$ | Bruno Frédérich ${ }^{1}$}

${ }^{1}$ Laboratory of Functional and Evolutionary Morphology, FOCUS, University of Liège, Liège, Belgium

${ }^{2}$ Department of Ecology and Evolutionary Biology, University of California Santa Cruz, Santa Cruz, California

${ }^{3}$ Laboratory of Oceanology, FOCUS,

University of Liège, Liège, Belgium

\section{Correspondence}

Laura Gajdzik, Laboratory of Functional and Evolutionary Morphology, FOCUS, University of Liège, Liège, Belgium.

Email: laura.gajdzik@gmail.com

\section{Present Address}

Laura Gajdzik, TrEnD Laboratory, School of Life and Molecular Science, Curtin University, Perth, Western Australia, Australia

\section{Funding information}

F.R.S-FNRS, Grant/Award Number: 24880335; FULBRIGHT commission, Grant/ Award Number: 15151491; "Concours de bourse de voyage 2014" of the WalloniaBrussels Federation

\begin{abstract}
Genetic diversity is essential for species persistence because it provides the raw material for evolution. For marine organisms, short pelagic larval duration (PLD) and small population size are characteristics generally assumed to associate with low genetic diversity. The ecological diversity of organisms may also affect genetic diversity with an expected corollary that more restricted habitat and dietary requirements could lead to a reduced genetic diversity because of pronounced genetic structuring. Here, we tested whether groups of species with narrower trophic niches displayed lower genetic diversity than those with broader niches. In order to test those predictions, we used different trophic guilds (i.e., groups of species having similar trophic habits) of coral reef damselfishes in Moorea (French Polynesia) for which we determined their genetic diversity using restriction site-associated DNA sequencing (RADseq) and their trophic ecology with stomach contents and stable isotope data. We found that pelagic feeders- the guild picking zooplankton in the water columnexhibited the lowest genetic diversity despite having the longest PLD and the largest population size. This guild had also the lowest variation in habitat characteristics and dietary composition compared to benthic feeders (i.e., those mainly grazing on algae) and the intermediate group (i.e., those feeding on zooplankton, filamentous algae and small benthic invertebrates). Our findings highlight the association between trophic ecology and genetic diversity that should be more commonly investigated in population genetics.

\section{KEYWORDS}

ecological diversity, genetic diversity, population genetics, RADseq, stable isotope, stomach content
\end{abstract}

\section{1 | INTRODUCTION}

Genetic diversity is one fundamental source of biodiversity on Earth and provides the raw material for evolution (Fisher, 1930; Hughes, Inouye, Johnson, Underwood, \& Vellend, 2008). It may be viewed as the link between evolutionary and ecological processes (Selkoe et al., 2016). As long as variation in ecologically important traits exists (e.g., growth rate, competitive ability), the amount of genetic diversity at any level can induce drastic ecological effects within a community. For example, it was shown that the genotype of a plant may drive both composition and structure of the multitrophic arthropod community (Johnson \& Agrawal, 2005), and reduced genetic diversity at the producer level may affect the wider food web of consumers (Jones et al., 2011).

Among other factors (e.g., population history including events of bottleneck or extirpation/colonization), the influence of two main biological traits on the patterns of genetic diversity has been broadly investigated in marine organisms: (a) the pelagic larval duration (PLD), defined as the period of time that larvae spend in the water column before settling on a fixed habitat after either hatching 
or spawning (Selkoe \& Toonen, 2011), and (b) the population size, especially the effective population size $\left(N_{\mathrm{e}}\right)$, which corresponds to the average number of individuals per generation contributing genes to the next generation (Ovenden et al., 2016). Pelagic larval duration is generally assumed to be a measure of dispersal potential, although doubts have emerged regarding its explanatory power on population structure as many variables can overshadow the simple metric of PLD (e.g., larval behaviour, oceanographic current; Selkoe \& Toonen, 2011). A short PLD is expected to induce an increased population differentiation over fine spatial scales because larvae settle close to their natal habitats (Planes, Doherty, \& Bernardi, 2001). In contrast, a higher PLD would yield greater dispersal and less genetic population structure (Helfman, Collette, Facey, \& Bowen, 2009; O'Donnell, Beldade, Mills, Williams, \& Bernardi, 2016) by increasing gene flow and perhaps may result in higher genetic diversity. Likewise, population size may influence genetic diversity because larger population size may counter deleterious effects of inbreeding (Soulé, 1987) and should be, on average, more polymorphic (Bazin, Glémin, \& Galtier, 2006).

Aside from these traits, the habitat and dietary characteristics of organisms may also impact their population structure and genetic diversity. The corollary is that habitat specialists are often found in patchier/more fragmented areas, which can limit gene flow and reduce their genetic diversity in contrast to habitat generalists (Janecka et al., 2016; Li, Jovelin, Yoshiga, Tanaka, \& Cutter, 2014). Similarly, the restricted dietary niche breadth of specialists may induce genetic differentiation and a lower genetic diversity compared to dietary generalists (Gaete-Eastman, Figueroa, Olivares-Donoso, Niemeyer, \& Ramírez, 2004). Most of these aforementioned studies only used one of these two ecological attributes to predict differences in genetic diversity and conducted their analysis at the species level. These choices could lead to several potential biases because they rely on certain assumptions (e.g., the firm identification of true generalists, a reciprocal degree of habitat and dietary specialization) and do not consider the dynamic processes characterizing species living in a community such as the competitive interactions. To overcome these possible issues and simultaneously grasp any variability in both diet and habitat, one might find it more appropriate to use groups of species that exploit the same class of environmental resources in a similar way (i.e., guilds; Root, 1967). Guilds offer two main advantages: (a) They are similar in their trophic habits but may vary in their habitat characteristics, and (b) they represent hierarchical structures within a community that are useful in comparative analysis (Blondel, 2003; Elliott et al., 2007). Consequently, guilds rely more directly on mechanisms driving diversity (Boyero et al., 2011) as they can help to decipher mechanisms of coexistence and resource sharing, and to describe the community in a more consistent manner.

Defining the degree of habitat and diet variability of organisms can be achieved with the evaluation of their isotopic niches that reflect trophic ecology, including the origin of food sources, trophic interactions and microhabitat requirements (e.g., Bearhop, Adams,
Waldron, Fuller, \& Macleod, 2004; Cucherousset \& Villéger, 2015; Fry, 2002; Newsome, Martinez del Rio, Bearhop, \& Phillips, 2007; Rigolet, Thiébaut, Brind'Amour, \& Dubois, 2015; Layman et al., 2012). A wider isotopic niche is generally assumed to be associated with more diverse trophic and habitat requirements. By analogy with Bearhop et al. (2004), wide-ranging individuals in terms of habitat characteristics (i.e., foraging in heterogeneous environments) with or without a less constrained diet should exhibit broader isotopic niches than populations composed of individuals with more limited requirements in those attributes. Nevertheless, when translating the isotopic niche into a combined trophic-habitat niche, additional information should be appraised and may include stomach content data (i.e., widespread technique to discriminate prey ingested; Hyslop, 1980) and other environmental information. Isotopic niches can be considered as general proxies of the prey-consumer (i.e., dietary interactions) and consumer-habitat relationships. Despite their advantages, there is an overall scarcity of integrative research exploring the link between genetic and trophic ecology, especially in coral reefs.

With 415 species distributed worldwide(Frédérich \& Parmentier, 2016; Fricke, Eschmeyer, \& van der Laan, 2018), Pomacentridae (damselfishes) are abundant members of the coral reef fish fauna. Almost all damselfish species exhibit a bipartite life cycle with a pelagic, dispersive larval phase followed by a benthic adult stage with a limited home range (Leis, 1991). Damselfishes also display an ecological partitioning as species can be grouped according to their trophic habits: (a) pelagic feeders that pick zooplankton, (b) benthic feeders that mainly graze on algae and (c) an intermediate group that feed on zooplankton, filamentous algae and small benthic invertebrates (Frédérich, Fabri, Lepoint, Vandewalle, \& Parmentier, 2009; Frédérich, Olivier, Gajdzik, \& Parmentier, 2016). These guilds are also associated with certain types of behaviours and habitats. For instance, pelagic feeders usually form aggregations that forage above the reef in the water column, while benthic feeders are solitary and live close to the reef bottom (Frédérich \& Parmentier, 2016; Frédérich et al., 2009). The intermediate group includes gregarious species which exhibit various habitat requirements, for example, obligate vs. facultative coral dwellers (Frédérich \& Parmentier, 2016; Gajdzik, Parmentier, Sturaro, \& Frédérich, 2016). Therefore, the ecology of Pomacentridae provides a good opportunity to explore whether genetic diversity varies among these trophic guilds.

The present study aims to explore the relationship between genetic and ecological diversity among trophic guilds using damselfishes from Moorea (French Polynesia) as our model of investigation. Genetic diversity of these guilds coexisting in sympatry and found within a phylogenetically constrained group (Pomacentridae) was measured with single nucleotide polymorphisms (SNPs), obtained through RADSeq (restriction site-associated DNA sequencing). Our aim was to test whether guilds with less variable habitat and dietary requirements (characterized by a narrower isotopic niche) displayed lower genetic diversity than those with more diverse characteristics in those ecological characteristics. We also further explored 


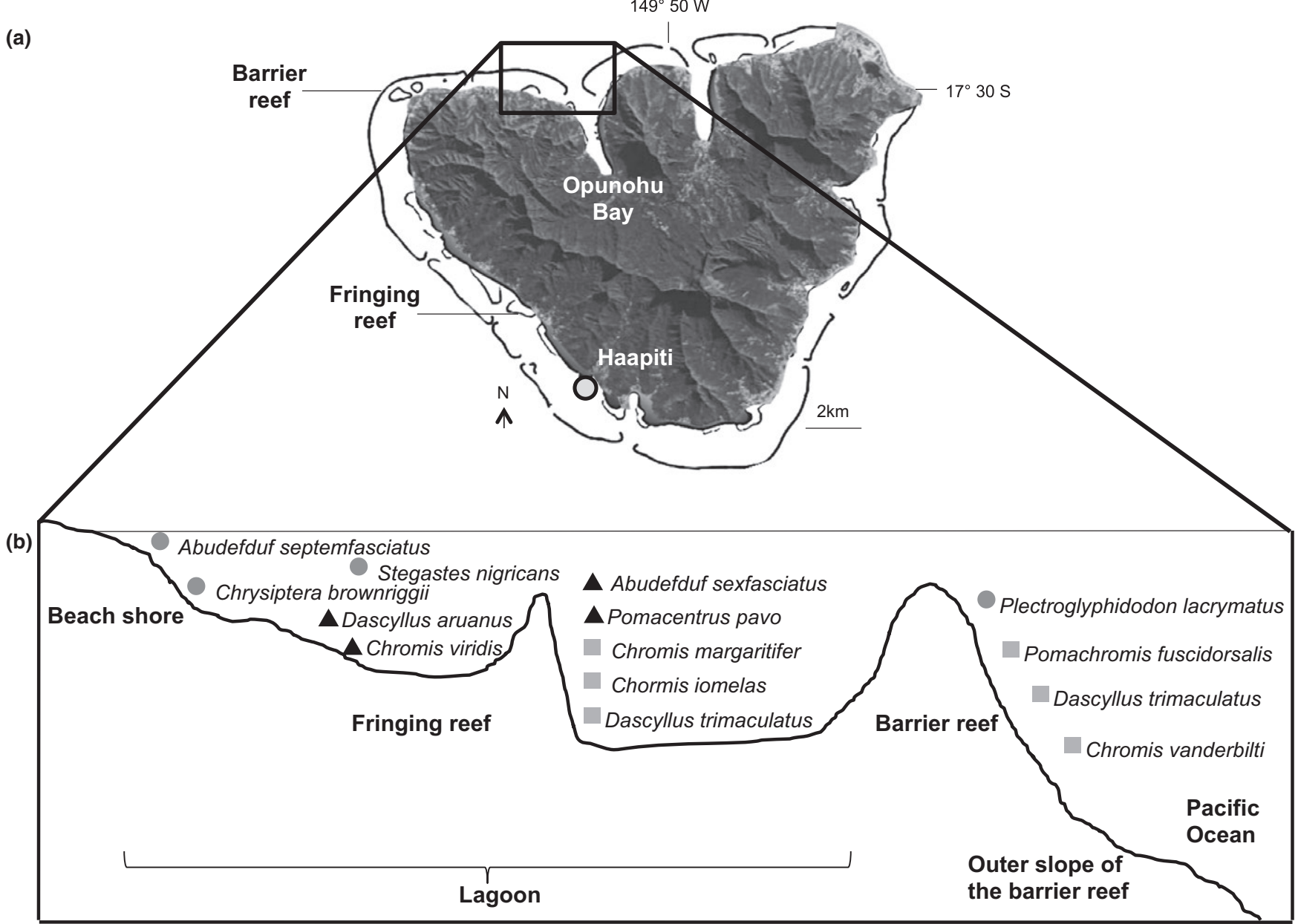

FIG URE 1 (a) Map of Moorea (French Polynesia) where the sampling of 13 damselfish species mainly occurred near Opunohu Bay. Some individuals of Abudefduf septemfasciatus were also collected along the shore in Haapiti (i.e., site indicated by a light grey circle). (b) Schematic representation of the coral reef ecosystem in Moorea (from the beach shore to the barrier reef) with an indication of the sites where the different species were collected along the reef-scape. This illustration was adapted from Gajdzik et al. (2016). The species' trophic guild assignment is as follows: dark grey circles for benthic feeders, black triangles for the intermediate group and light grey squares for pelagic feeders

whether PLD and population size were effective predictors of genetic diversity.

\section{MATERIALS AND METHODS}

\section{1 | Sampling}

In the present study, we used damselfish individuals collected by Gajdzik et al. (2016). These individuals were sampled in Moorea, an island located in the South Pacific $\left(17^{\circ} 30^{\prime} \mathrm{S}, 149^{\circ} 50^{\prime} \mathrm{W}\right.$; French Polynesia; Figure 1a). Ninety-four individuals belonging to $13 \mathrm{dam}$ selfish species were caught while scuba diving with the use of hand nets and clove oil $(40 \mathrm{mg} / \mathrm{L})$ or spear guns (Table 1). Sampling occurred from the shore to the outer slope of the barrier reef mainly near Opunohu Bay (North side of Moorea; Gajdzik et al., 2016). However, some individuals of Abudefduf septemfasciatus were also collected along the shore at Haapiti in the Southwest of the island
(Figure 1a; Gajdzik et al., 2016). Fishes were euthanized by an overdose (>400 mg/L) of MS-222 (tricaine methanesulfonate) and placed on ice in cool boxes when returned to the wet lab (Gajdzik et al., 2016). All samples were collected in accordance with the European Directive 2010/63/EU following the guidelines from the Animal Ethics Committee of the University of Liege (Belgium), and under the laws and regulations of French Polynesia.

Clips from the dorsal fins and gill rakers of each individual were preserved in $95 \%$ ethanol and stored in a freezer at $-20^{\circ} \mathrm{C}$ for genetic analysis. The stomach of each individual was removed and preserved in 70\% ethanol for further analysis (Gajdzik et al., 2016). Epaxial muscles were cut off, dried for $48 \mathrm{hr}$ at $60^{\circ} \mathrm{C}$ and ground into a homogeneous fine powder in an oven for stable isotope analysis (Gajdzik et al., 2016).

Although 94 individuals were used in all subsequent analyses presented in the main text, additional sets of 20, 81 and 89 fish individuals were also available for the genetic, stomach content and 


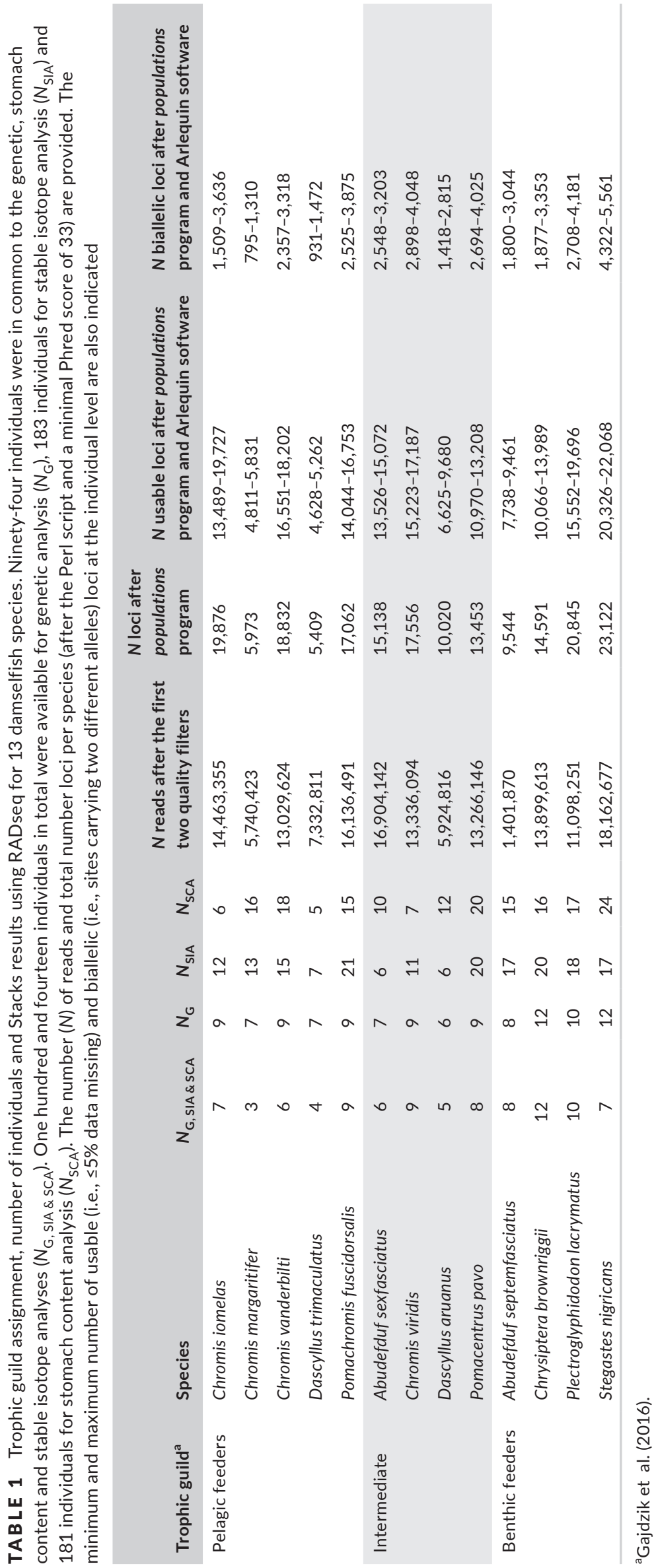


stable isotope analyses, respectively (Table 1). These sets of additional individuals were collected during the same sampling campaign and in the same reef areas.

\subsection{Genetic data set}

DNA was extracted from fin clips using DNeasy Blood \& Tissue kits (Qiagen) according to manufacturer's protocol. We constructed RAD libraries using a variation of the original protocol with the restriction enzyme Sbfl (Baird et al., 2008; Longo \& Bernardi, 2015; Miller et al., 2012; Miller, Dunham, Amores, Cresko, \& Johnson, 2007). The other main revisions are listed as follows.

Initial genomic DNA concentrations for each fish individual were 400 ng. Libraries were physically sheared on a Covaris S2 sonicator with an intensity of 5 , duty cycle of $10 \%$, cycles/burst of 200 and a cycle time of $30 \mathrm{~s}$. We carried out the final PCR amplification step in $50 \mu \mathrm{l}$ reaction volumes with 16 amplification cycles. Ampure XP beads (Agencourt) were used for each purification step and size selection. Samples used in this study were sequenced in two libraries, one containing 90 individually barcoded samples and a second one with 26 barcoded individuals. Each library was sequenced in a single lane on an Illumina HiSeq 2000 at the Vincent J. Coates Genomics Sequencing Laboratory at UC Berkeley (USA). Then, we applied Perl scripts to trim the raw reads to 92 base pairs (bp) on the $3^{\prime}$ end, quality filtered and demultiplex them according to the $6 \mathrm{bp}$ unique barcodes. Reads with Phred scores of $<33$ were discarded. The barcodes and restriction site residues ( $6 \mathrm{bp}$ ) were removed from the $5^{\prime}$ end, and this resulted in a final sequence length of $80 \mathrm{bp}$.

The software program STACKS version 1.29 (Catchen, Amores, Hohenlohe, Cresko, \& Postlethwait, 2011; Catchen, Hohenlohe, Bassham, Amores, \& Cresko, 2013) was used to identify orthologous sequences among damselfish taxa. For each species, the DENOVO MAP.PL program was first executed and used to run each of the three components (ustacks to build loci and call SNPs de novo in each sample, cstacks to create a catalog of all loci across the population and sstacks to match each sample against the catalog) individually in a Stacks pipeline. Parameter settings were as follows: (a) a minimum stack depth ( $m$ command) of 3 , (b) a maximum of three mismatches per loci for each individual ( $M$ command) and (c) up to two mismatches between loci when building catalog loci ( $n$ command). We also ran various DENOVO_ MAP.PL iterations with different values of parameters for each species, but it did not change the overall outcome (see Supporting Information Table S1 and Figure S1). Using the POPULATION COmponent in Stacks, we further filtered the data set by retaining loci with a minimum depth of coverage set to 8 ( $\mathrm{m}$ command), which aligned in $\geq 80 \%$ of individuals ( $r$ command) in every species. We also tested whether setting the minimum stack depth to 10 and the missing locus rate to $\leq 5 \%$ ( $a$ command) would change the results, but it did not (results not shown). From these data sets and for each species, GENEPOP (Rousset, 2008) input files were generated using the POPULATIONS component in Stacks with the write single_snp option implemented. To measure the genetic diversity for each trophic guild, we considered each individual as a population in the
GENEPOP files, which were converted afterwards using the program PGDSPIDER V.2.1.0.3 (Lischer \& Excoffier, 2012). As an additional quality filter for SNPs, we tested for departures from linkage disequilibrium (LD) expectations between each pair of loci for each species and found that none were in LD (results not shown). Testing for LD was done using the GENEPOP files and performed with the $\mathrm{R}$ packages DARTR V.1.0.4 (Gruber, Unmack, Berry, \& Georges, 2018), HWXTEST v.1.1.7 (Engels, 2009), ADEGENET v.2.1.1 (Jombart \& Ismaïl, 2011) and ADE4 v.1.7-10 (Dray, Dufour, \& Chessel, 2007). Significance level s were adjusted to the total number of pairwise comparisons for each species (i.e., Bonferroni correction). For each species, we then calculated the index of expected heterozygosity $\left(H_{\mathrm{e}}\right)$ that represents the proportion of biallelic loci (i.e., carrying two different alleles) within each individual (Hughes et al., 2008). Heterozygosity was calculated with the program ARLEQUIN V.3.5.2.2. (Excoffier \& Lischer, 2010), which further filtered out loci with $\geq 5 \%$ missing data in each individual. To test the robustness of our results when running the DENOVO_ MAP.PL program separately for each species, we calculated the heterozygosity by only using the loci shared among the 94 damselfish individuals from the 13 studied damselfish species. For that purpose, a new DENOVO_ MAP.PL program was executed on these 94 individuals with the aforementioned parameters: a minimum stack depth ( $m$ command) of 3, a maximum of three mismatches per loci for each individual ( $M$ command) and up to two mismatches allowed between loci when building catalog ( $n$ command). Once created, we identified the loci shared among all individuals using the Catalog option on the Stacks website. The 995 homologous loci were then exported into a whitelist. After that, we generated one GENEPOP file per species (in which one individual represents one population) using the POPULATIONS Component in Stacks with the write single_snp option and the whitelist containing the 995 homologous loci. The use of this whitelist meant that the POPULATIONS program only processed the loci provided in the list, ignoring all other loci. After that, GENEPOP files were converted with the program PGDSPIDER V.2.1.0.3 (Lischer \& Excoffier, 2012) and heterozygosity was computed with the program ARLEQUIN v.3.5.2.2. (Excoffier \& Lischer, 2010). In addition, heterozygosity can be computed directly at the species level and represents a genetic variation within a given population for each species. This mean heterozygosity corresponds thus to the average proportion of biallelic loci in all individuals of a given population (i.e., for each species).

\section{3 | PLD and population size traits}

Pelagic larval duration (PLD) of studied species was gathered from the scientific literature (Thresher, Colin, \& Bell, 1989; Wellington \& Victor, 1989). The mean population size $(N)$ of each damselfish species was based on a 12-year survey conducted in Moorea, where visual fish transects were repeated annually (Brooks, 2016). The effective population size $\left(N_{\mathrm{e}}\right)$ was calculated using Tajima's Equation: $\pi(\mathrm{Pi})=4 \mathrm{~N}_{\mathrm{e}} \mu$, where $\pi$ is the nucleotide diversity (obtained using Stacks) and $\mu$ is the mutation rate per site per generation (Tajima, 1983). This rate has been estimated at $10^{-8}$ to $10^{-9}$ for fish RAD sequences (Brumfield, Beerli, Nickerson, \& Edwards, 2003; Zhang et al., 2016). For coral reef 
damselfishes, generation time generally varies between 1 and 2 years (Fauvelot, Lemaire, Planes, \& Bonhomme, 2007; Froese \& Pauly, 2016; Underwood, Travers, \& Gilmour, 2012). Consequently, for our calculations, we used the mean value of $5 \times 10^{-9}$ as our mutation rate and the mean value of 1.5 years as our generation time.

\section{4 | Trophic ecology}

Full information about the collection of trophic data from stomach contents and stable isotope ratios for the 13 studied damselfish species are provided in Gajdzik et al. (2016). Here, we briefly describe these methods.

\subsection{1 | Stomach contents}

Individual stomachs were opened in order to identify prey items and counted under a binocular microscope Leica MS 5. Out of the 94 individuals, 10 stomach contents were full of unidentifiable amorphous material and were thus discarded from the analysis. Food sources were classified into six categories reflecting different functional types of food items: zooplankton, benthic algae, vagile invertebrates, rubble (i.e., corals or rocks), benthic egg and insect. Additional details about each food category can be found in Gajdzik et al. (2016). The number of items in each functional food category was recorded and expressed as a percentage to the total number of items for each individual stomach (Hyslop, 1980).

\subsection{2 | Stable isotopes}

Stable isotope ratios of carbon $\left({ }^{13} \mathrm{C} /{ }^{12} \mathrm{C}\right)$, nitrogen $\left({ }^{15} \mathrm{~N} /{ }^{14} / \mathrm{N}\right)$ and sulphur $\left({ }^{34} \mathrm{~S} /{ }^{32} \mathrm{~S}\right)$ of each damselfish individual were measured with an isotope ratio mass spectrometer (IsoPrime100; Isoprime, UK) coupled in continuous flow to an elemental analyser (vario MICRO cube, Elementar, Germany). These ratios were conventionally expressed as $\delta$ values in \%o (Coplen, 2011), and respective certified reference materials from the International Atomic Energy Agency (IAEA, Vienna, Austria) were sucrose (IAEA-C6, $\delta^{13} \mathrm{C}=-10.8 \pm 0.5 \%$; mean $\pm S D$ ), ammonium sulphate (IAEA-N2, $\quad \delta^{15} \mathrm{~N}=20.3 \pm 0.2 \%$ ) and silver sulphide (IAEA-S1, $\left.\delta^{34} S=-0.3 \pm 0.3 \% \circ\right)$. These reference materials were calibrated against the international references Vienna Pee Dee Belemnite for carbon, Atmospheric Air for nitrogen and Canon Diablo troilite for sulphur. Hundreds of replicate assays of internal laboratory standards indicate measurement errors of $\pm 0.2 \%$ o for $\delta^{13} \mathrm{C}$ and $\pm 0.3 \%$ 。 for $\delta^{15} \mathrm{~N}$ and $\pm 0.5 \%$ o for $\delta^{34} \mathrm{~S}$.

\section{5 | Statistical analyses}

We conducted our study at the guild level, by comparing the genetic, dietary (i.e., stomach contents), and isotopic data (i.e., carbon, nitrogen and sulphur stable isotope ratios) of 94 individuals belonging to three trophic guilds from a given damselfish assemblage (Supporting information Tables S2 and S3). The guild classification corresponds to the one identified by Gajdzik et al. (2016), wherein the trophic ecology of these 13 damselfish species was studied with thorough analyses. Although both Abudefduf sexfasciatus and Chromis viridis are generally considered as pelagic feeders (e.g., Frédérich et al., 2009; Frédérich, Cooper, \& Aguilar-Medrano, 2016; Kuo \& Shao, 1991; Wyatt, Waite, \& Humphries, 2012), we used the trophic guild assignment of their respective populations in Moorea where they displayed an intermediate-feeding strategy (Gajdzik et al., 2016).

\subsection{1 | Genetic diversity}

Between 1.4 and 18 million sequence reads (after the two first quality filters) produced between $\sim 5,400$ and $\sim 23,000$ total loci per species. In all individuals for all 13 species, the number of usable loci (i.e., $\leq 5 \%$ data missing) varied between $\sim 4,600$ and $\sim 22,000$ and the number of biallelic loci were between $\sim 800$ and $\sim 5,500$ (Table 1).

We tested for significant differences in heterozygosity $\left(H_{\mathrm{e}}\right)$ among trophic guilds using an ANOVA (given that assumptions of normality and homogeneity of variances were met) and then conducted pairwise comparisons with Tukey's post hoc tests in $R(R$ Core Team, 2011). We also performed a chi-square test to determine whether observed genetic data significantly differed from theoretical expectations for each trophic group and after that, we conducted pairwise comparisons.

Kinship coefficients for each pair of individuals for every species were also calculated because species' individuals were sampled within the same areas in the coral reef ecosystem of Moorea. This sampling strategy could increase the chance of relatedness among individuals and thus bias the estimation of genetic diversity. Consequently, we estimated Kinship coefficients in GENODIVE v.2.0b20 (Meirmans \& Van Tienderen, 2004) with respect to the allele frequencies for each species' data set, so they provide an estimation of relative relatedness between each pair of individuals (Loiselle, Sork, Nason, \& Graham, 1995).

\subsection{2 | PLD and population size traits}

Significant differences of PLDs and population sizes ( $N$ based on visual censuses and $N_{\mathrm{e}}$ ) among trophic groups were tested with ANOVA tests after square-root and logarithmic transformations, respectively, in order to meet assumptions of normality and homogeneity. When significant difference was found $(p<0.05)$, pairwise comparisons were conducted with Tukey's post hoc tests in $\mathrm{R}$ ( $\mathrm{R}$ Core Team, 2011).

\subsection{3 | Trophic ecology: Stomach content analysis}

Stomach content analysis was first applied to determine the diet breadth by studying different functional types of prey. We applied the Roughgarden (1974) concept and calculated the total niche width (TNW) that represents the full range of food resources 
used by a group (Bolnick, Svanbäck, Araújo, \& Persson, 2007). Calculation of TNW is biased by the inclusion of more individuals that only contain prey items from one functional group in their stomachs (Bolnick, Yang, Fordyce, Davis, \& Svanbäck, 2002), we therefore conducted a second analysis with 181 individual stomach contents that were evenly distributed in each trophic guild. Monte Carlo simulations were generated on TNWs with $10^{6}$ iterations through the WTCMC function in $\mathrm{R}$ with package RINSP V.1.2 (Zaccarelli, Bolnick, \& Mancinelli, 2013). We then tested for significant differences among these indices by examining if they had $\leq 5 \%$ probability of overlapping based on their distributions (i.e., Z-score).

\subsection{4 | Trophic ecology: Stable isotope analysis}

Stable isotopes provide information on the diet of fishes, foraging strategies and habitat partitioning among the reef-scape (Gajdzik et al., 2016). We used the isotopic richness (IRic) metric that is defined as the smallest convex hull area comprising the isotope ratios of damselfish individuals and represents the isotopic niche width of each trophic guild (Cucherousset \& Villéger, 2015). Isotopic richness was computed on three stable isotope ratios $\left(\delta^{13} \mathrm{C}, \delta^{15} \mathrm{~N}\right.$ and $\left.\delta^{34} \mathrm{~S}\right)$ with commands derived from the script "si_div" (Cucherousset \& Villéger, 2015) in R packages GEOMETRY v.0.3 - 6 (Habel, Grasman, Gramacy, Stahel, \& Sterratt, 2015), APE v.3.4 (Paradis, Claude, \& Strimmer, 2004). A bootstrap procedure was performed on IRics with $10^{4}$ iterations. It consisted of randomly resampling a subsample of individuals (each one of the generated groups having a number of individuals equal to the number of the real population) from each trophic group with replacement to give some uncertainties in IRics. If the convex hull could not be calculated for any randomly selected subsamples, a new random subsample was chosen. We tested for significant differences among trophic groups by examining whether they had $\leq 5 \%$ probability of overlapping based on their distributions (i.e., z-score test; Gajdzik, et al., 2018a). Given that the IRic is very sensitive to sample size, we also estimated it with more damselfish individuals ( $n=183$ ) that were caught during the same sampling campaign. Additionally, using these 183 individuals, we computed the IRic for each of the 13 damselfish species.

\subsection{5 | Relationship between isotopic and genetic data}

Given that we had three isotopic ratios and a value of $H_{e}$ for each of the 94 individuals, we sought to test for a correlation between the isotopic and genetic data using a reduced major axis (RMA) regression. This analysis fits a regression line when there is no clear choice of which variable is the dependent one (Clarke, 1980). Before performing this test, we reduced the three isotopic values $\left(\delta^{13} \mathrm{C}, \delta^{15} \mathrm{~N}\right.$ and $\delta^{34} \mathrm{~S}$ ) for each fish individual into one value and this step was achieved with a principal coordinates analysis (PCoA; Davis, 1986) in the program PAST v.3.14 (Hammer, Harper, \& Ryan, 2001). We kept the scores of the first PCoA, which captured $73 \%$ of the information related to the isotopic composition. We also explored for any association between heterozygosity and isotopic composition at the species level. This test was achieved using the aforementioned framework, but was based on the maximum number of individuals available for each species and on the first PCoA that grasped $75 \%$ of the isotopic information.

\section{3 | RESULTS}

\section{1 | Genetic diversity}

Genetic diversity (heterozygosity, $H_{\mathrm{e}}$ ) was significantly different among trophic groups (ANOVA, $F_{2,91}=15.27, p=1.92 \times 10^{-6}$ ). Pelagic feeders displayed the lowest genetic diversity level with a median value of 0.18 (Figure 2). Results were analogous when adding more individuals $(n=114$; ANOVA after exponential transformation, $F_{2,111}=19.09, p=7.46 \times 10^{-8}$; Supporting Information Figure S2) and when only using 995 loci in common to all species ( $n=94$; ANOVA after logarithmic transformation, $F_{2,91}=13.31$, $p=8.50 \times 10^{-6}$; Supporting Information Figure S3). In addition, chisquare tests showed that there was a lower frequency in the distribution of $\mathrm{H}_{\mathrm{e}}$ of individuals within pelagic feeders, which was also significantly different from the one of the intermediate group or the one of benthic feeders $\left(\chi^{2}=8.64, d f=1, p=3 \times 10^{-3}\right.$ and $\chi^{2}=10.10$, $d f=1, p=1 \times 10^{-3}$, respectively). Additionally, the overall pairwise kinship values were low, suggesting that our results were not biased by an abundance of relatives (results not shown). Furthermore, computing the heterozygosity directly at a species level further sustained that fish species in French Polynesia exhibited an overall low genetic diversity (Supporting Information Table S4).

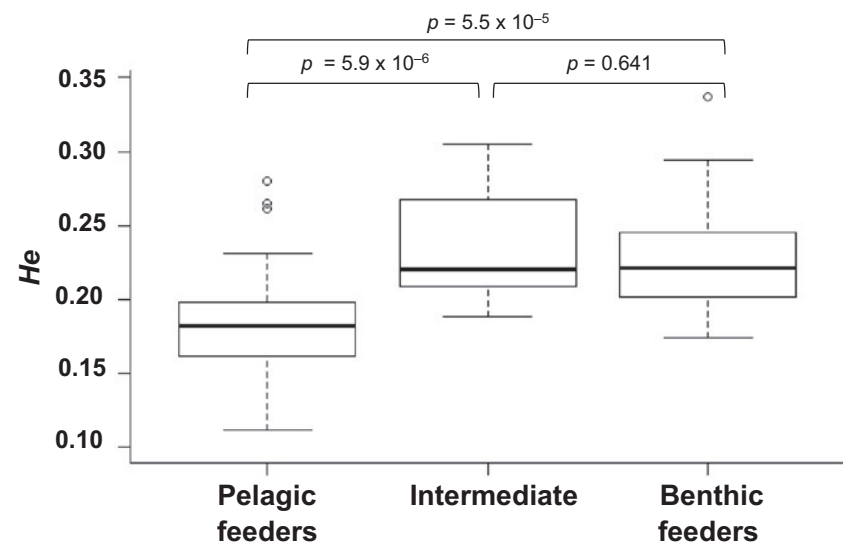

FIGURE 2 Genetic diversity of the three trophic guilds based on 94 individuals that belong to 13 damselfish species. Genetic diversity was measured with the heterozygosity index $\left(H_{\mathrm{e}}\right)$. Twentynine individuals belonged to the pelagic-feeding guild, 28 to the intermediate group and 37 to benthic feeders (Table 1). Median values are represented by black lines. The significance level ( $p$ values, $p$ ) between trophic guilds is also indicated 


\section{2 | PLD and population size traits}

Trophic guilds differed in their mean PLD and population size. The PLD of pelagic feeders (median value of 28.5 days) was significantly higher than the PLD of the two other guilds (ANOVA, $F_{2,9}=10.60$, $p=4 \times 10^{-3}$; Figure 3a). Similarly, visual censuses $(N)$ estimated the average density of damselfish pelagic feeders at 8.1 individuals per $100 \mathrm{~m}$. This population size was 3-8 times higher than those of the two other trophic guilds (ANOVA, $F_{2,10}=5.80, p=2 \times 10^{-2}$; Figure $3 \mathrm{~b}$; Supporting Information Table S4). While the population size of pelagic feeders was significantly different from the population

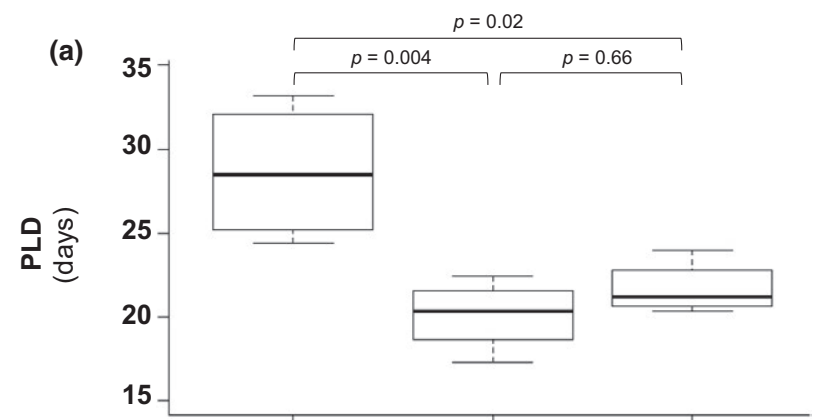

(b)
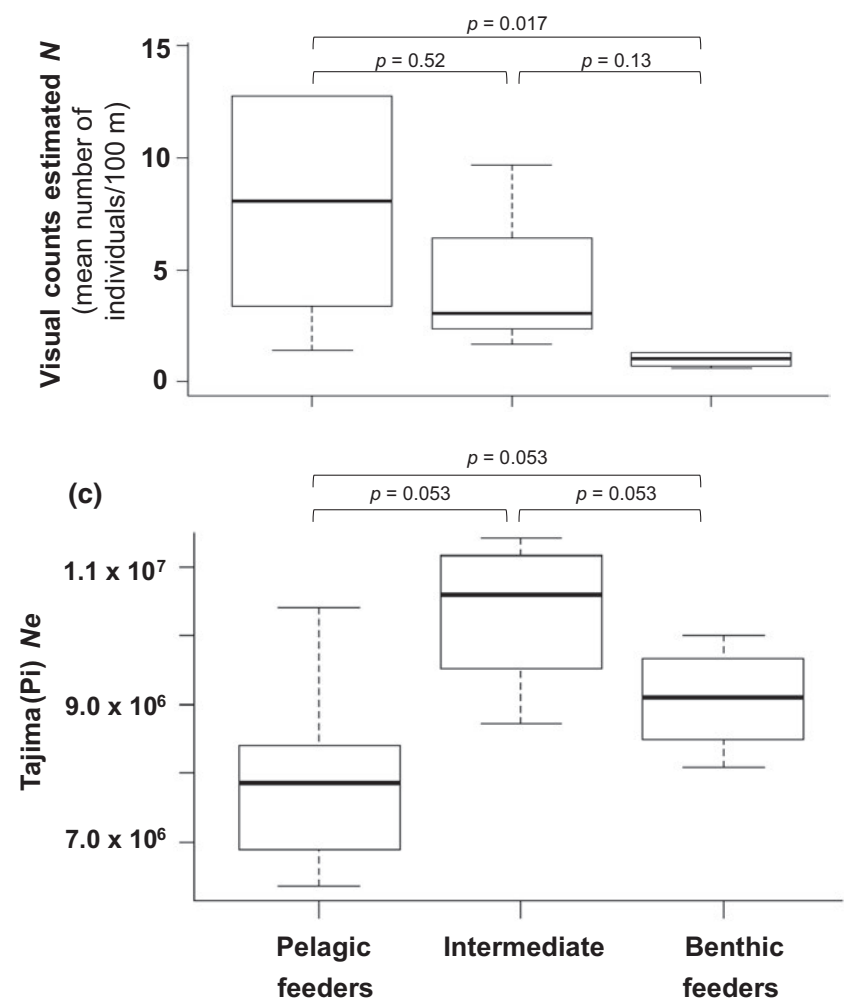

FIGURE 3 Values of the commonly used ecological traits for each trophic guild: (a) Pelagic larval duration (PLD), (b) population size $(N)$ based on visual censuses and (c) Tajima effective population size $\left(N_{\mathrm{e}}\right)$ were estimated on the 13 damselfish species (n) grouped per trophic group ( $n=5$ for pelagic feeders, $n=4$ for the intermediate group and $n=4$ for benthic feeders; Supporting Information Table S4). Median values are represented by black lines. The significance level ( $p$-values, $p$ ) between trophic guilds is also indicated

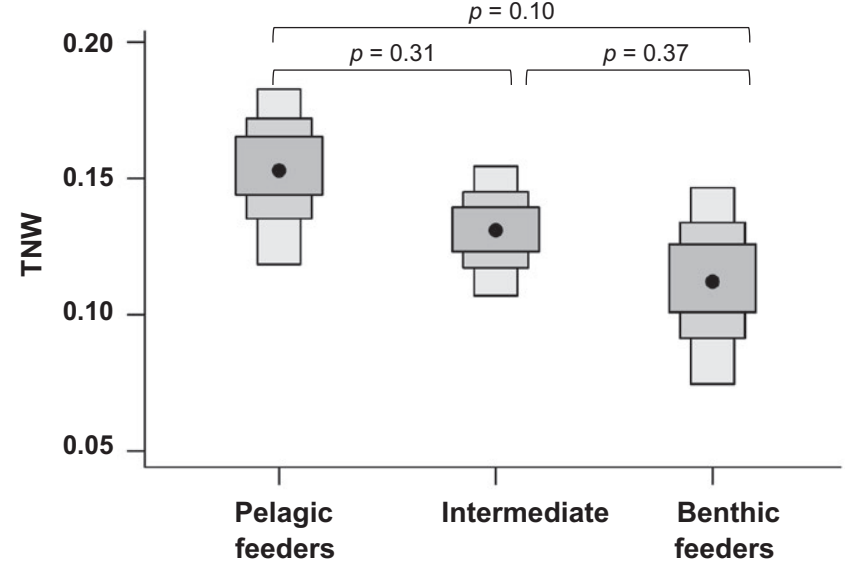

FIGURE 4 Diet breadth of the three trophic guilds based on stomach content data and measured with the total niche width (TNW). This metric was calculated on the 94 individuals that belong to 13 species. The number of individuals was 24 for pelagic feeders, 24 for the intermediate group and 36 to benthic feeders (Table 1), as 10 individuals had empty stomachs (see Results). Total niche widths were computed with $10^{6}$ Monte Carlo simulations. Boxplots display $50 \%, 75 \%$ and $95 \%$ confidence intervals from dark grey to light grey, respectively. Mean values are indicated by black dots. The significance level ( $p$-values, $p$ ) between trophic guilds is also indicated

size of benthic feeders (1.1 damselfish individuals per $100 \mathrm{~m}$ ), it did not differ from the population size of the intermediate group and this could be related to its high variance. Although there was a tendency for lower effective population size $\left(N_{\mathrm{e}}\right)$ for pelagic feeders (median value of $7.85 \times 10^{6}$ ) compared to the two other trophic guilds (median value of $9.10 \times 10^{6}$ and $1.06 \times 10^{7}$, respectively), no significant differences were found (ANOVA, $F_{2,10}=3.86, p=0.053$; Figure 3c; Supporting Information Table S4).

\section{3 | Trophic ecology}

\subsection{1 | Stomach content data}

The TNW values did not differ significantly among trophic guilds. The $95 \%$ confidence interval $\left(\mathrm{Cl}_{95}\right)$ ranged from 0.12 to 0.18 for pelagic feeders and from 0.07 to 0.15 for benthic feeders (Figure 4). Nevertheless, when adding twice more individuals, the TNW of pelagic feeders increased (mean $\pm S D ; 0.18 \pm 0.01$ ) with a $\mathrm{Cl}_{95}$ ranging between 0.17 and 0.20 , and was significantly different than TNWs of the two other trophic guilds (Supporting Information Figure S4).

\subsection{2 | Stable isotope data}

According to a previous work devoted to trophic partitioning of damselfishes at Moorea (Gajdzik et al., 2016), variation along the $\delta^{13} \mathrm{C}$ $\delta^{15} \mathrm{~N}$ axis illustrates fish diet and trophic interactions (Figure 5a), whereas segregation along the $\delta^{13} \mathrm{C}-\delta^{34} \mathrm{~S}$ axis mainly captures foraging locations and habitat partitioning (Figure $5 b$ ).

Significant differences were found among IRics of the three trophic guilds, which varied from $1.58 \pm 0.21$ (mean $\pm S D$ ) to $35.85 \pm 5.31$ 


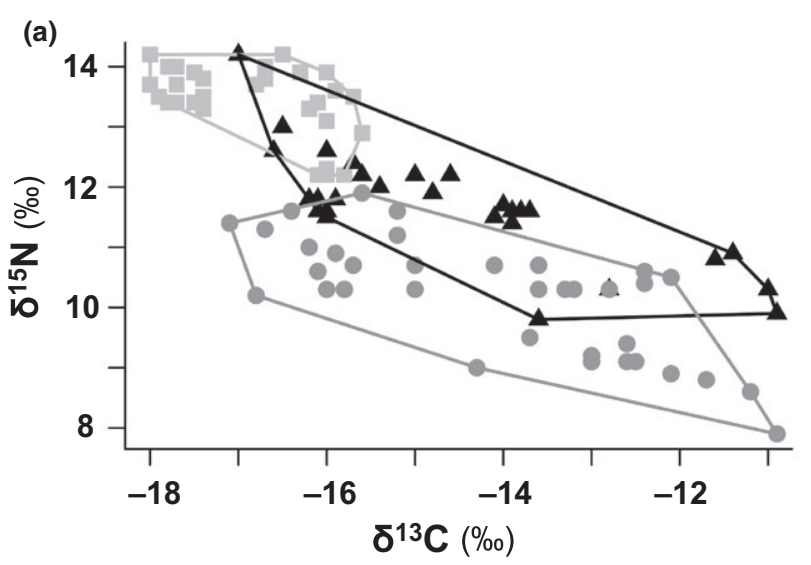

(b)
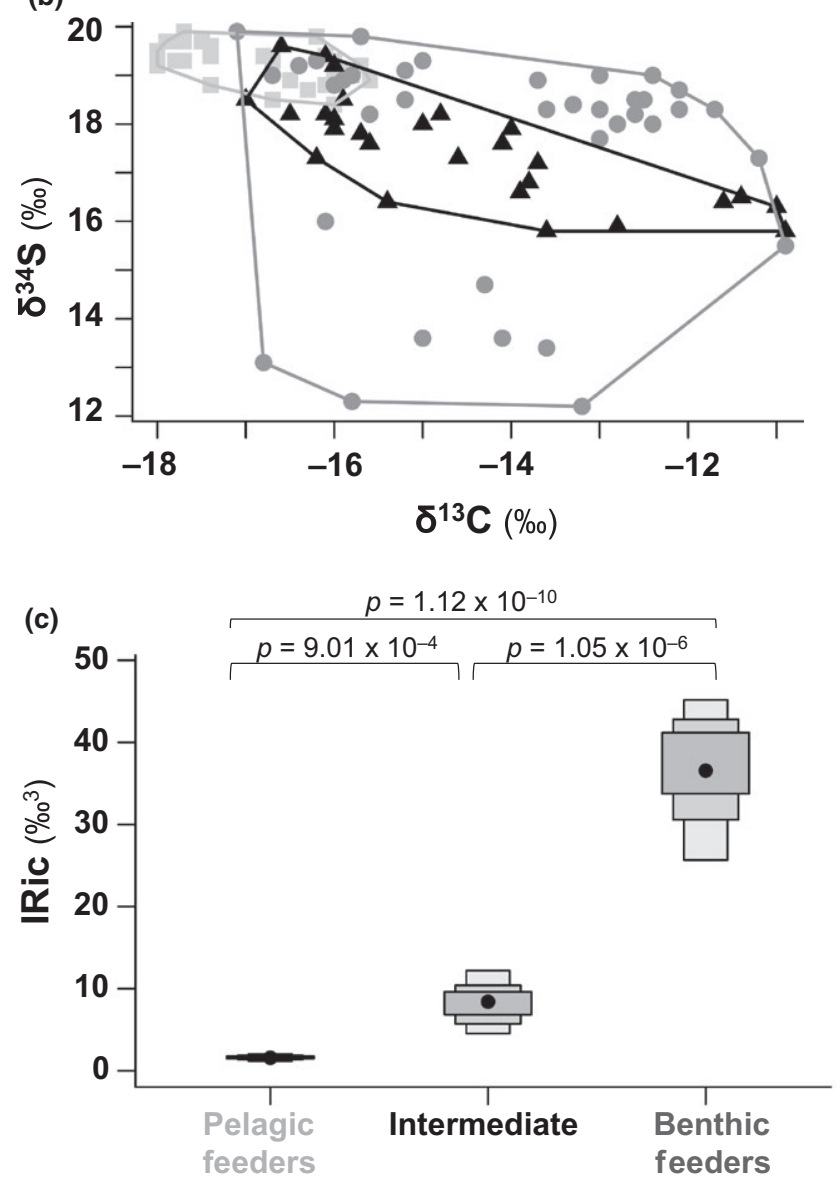

(mean $\pm S D$ ) for pelagic feeders and benthic feeders, respectively. These differences were confirmed when using more damselfish individuals ( $n=183$ ) that were evenly distributed in each trophic guild (Supporting Information Figure S5). Our results showed that pelagic feeders displayed the smallest convex hull volume [i.e., $\mathrm{Cl}_{95}=(1.11$; 1.95)] and the IRic of every pelagic-feeding species was also very small (between $0.04 \pm 0.03$ and $0.45 \pm 0.17$; Supporting Information Figure S6). In contrast, benthic feeders exhibited the largest $\mathrm{Cl}_{95}$ (between 23.94 and 44.39) and each benthic-feeding species occupied a large portion of the total isotopic space (between $0.73 \pm 0.23$ and $10.73 \pm 3.28$; Supporting Information Figure $\mathrm{S} 6$ ). The $\mathrm{Cl}_{95}$ of the IRic of the intermediate group (from 4.44 to 12.06 ) was in between those
FIGURE 5 Trophic ecology based on carbon $\left(\delta^{13} \mathrm{C}\right)$, nitrogen $\left(\delta^{15} \mathrm{~N}\right)$ and sulphur $\left(\delta^{34} \mathrm{~S}\right)$ stable isotope ratios estimating trophic ecology of damselfish guilds. (a) Biplot of $\delta^{13} \mathrm{C}$ and $\delta^{15} \mathrm{~N}$ and (b) biplot $\delta^{13} \mathrm{C}$ and $\delta^{34} \mathrm{~S}$ of all damselfish individuals that each belong to a trophic group (light grey squares for pelagic feeders, black triangles for the intermediate group and dark grey circles for benthic feeders), which graphically represent the convex hull (i.e., isotopic richness, IRic) for each guild. (c) IRics computed on three stable isotope ratios of the 94 studied individuals $(n)$ that were grouped per trophic guild ( $n=29$ for pelagic feeders, $n=28$ for the intermediate group and $n=37$ for benthic feeders). IRics were calculated with $10^{4}$ Monte Carlo simulations. Boxplots show $50 \%, 75 \%$ and $95 \%$ confidence intervals from dark to light grey, respectively. Mean values are represented by black dots. $p$-Values $(p)$ were based on models of posterior distributions (confidence intervals), indicated whether there was $<5 \%$ of overlap among all IRics

of the two other guilds (Figure $5 c)$. This group was composed of species that had either low values of IRic $(0.07 \pm 0.05)$ or among the highest ( $2.89 \pm 1.01$; Supporting Information Figure S6).

\subsection{Relationship between isotopic and genetic data}

Results of the RMA regression revealed that fish individuals having low value of $H_{e}$ had significantly smaller coordinate values along the first PCoA axis, which corresponded to lower $\delta^{13} \mathrm{C}$ values, higher $\delta^{15} \mathrm{~N}$ and higher $\delta^{34} \mathrm{~S}$ values. This test indicated that the isotopic composition and genetic diversity of the 94 damselfish

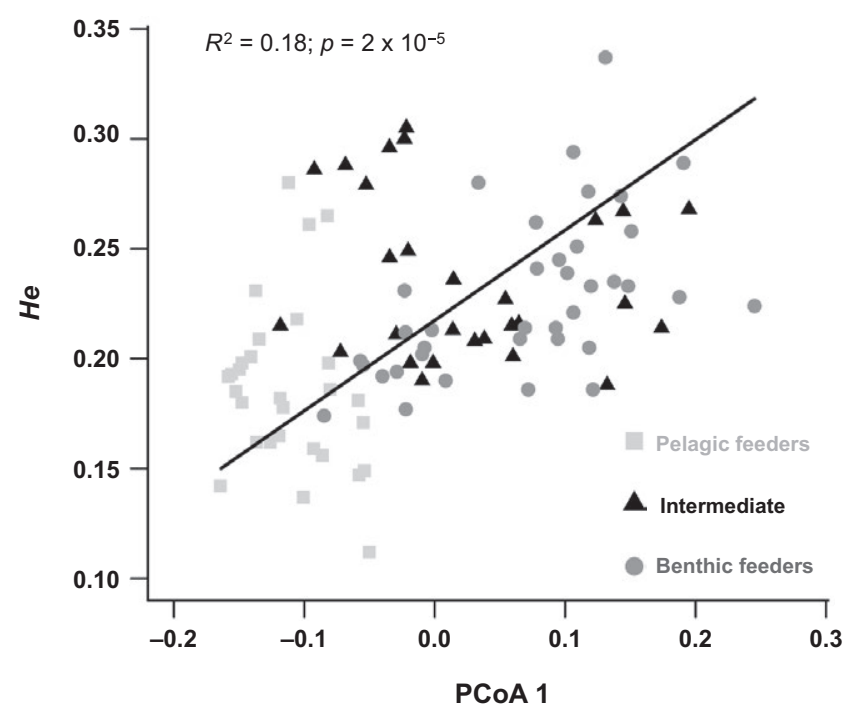

FIGURE 6 Illustration of the reduced major axis regression (RMA) between isotopic (i.e., coordinates along the first PCoA axis grasping the isotopic composition) and genetic data (i.e., heterozygosity, $\mathrm{H}_{\mathrm{e}}$ ). The linear regression was based on the 94 damselfish individuals $(n)$ that belonged to 13 damselfish species and were coloured using their trophic guild assignment $(n=29$ for pelagic feeders, $n=28$ for the intermediate group and $n=37$ for benthic feeders) 
individuals were correlated $\left(R^{2}=0.18 ; p=2 \times 10^{-5}\right.$; Figure 6). Likewise, a significant association between $\mathrm{H}_{e}$ and isotopic composition was found for each species $\left(R^{2}=0.32 ; p=0.04\right.$; Supporting Information Figure S7).

\section{4 | DISCUSSION}

This study explores the potential congruence between genetic diversity and traits of trophic guilds. Some discrepancies appeared when comparing genetic diversity and trait values related to the PLD and population size. However, our data lend strong support for a link between genetic diversity and trophic ecology in coral reef damselfishes.

\section{1 | The particular case of Pomacentridae in French Polynesia}

Prior to dissecting our results, we acknowledge the reduced genetic diversity of reef fishes in French Polynesia compared to New Caledonia and the Great Barrier Reef (e.g., Gaither et al., 2011; Liu, Chang, Borsa, Chen, \& Dai, 2014; Messmer, Jones, Munday, \& Planes, 2012), which was further confirmed by the heterozygosity of the 13 studied damselfish species from Moorea (Supporting Information Table S4). This phenomenon could be attributed to both a peripheral location and geographic isolation of the French Polynesian region (Briggs \& Bowen, 2012; Gaither, Toonen, Robertson, Planes, \& Bowen, 2010). The southerly flowing South Equatorial Current (Bonjean \& Lagerloef, 2002) may constitute an effective barrier further separating the populations of the Society Islands from the other central West Pacific population (Liu et al., 2014). This isolation due to oceanographic currents is enhanced by limited gene flow (Gaither et al., 2010), which can in turn limit the levels of genetic diversity in these peripheral populations of fishes in French Polynesia. However, despite the overall low genetic diversity, we still found differences in heterozygosity among the different trophic guilds (Figure 2).

In addition, the studied peripheral populations of damselfishes in Moorea are composed of different sets of species that cluster into three main trophic guilds. While benthic feeders and the intermediate group comprise species belonging to several distinct subfamilies, pelagic feeders group closely related species (3 Chromis spp. and 1 Dascyllus sp.; Table 1) from the Chrominae subfamily. Consequently, we cannot completely rule out the effect of phylogenetic proximity on our estimation of genetic diversity within the damselfish guilds, even if RADseq markers produced high-resolution population genomic data (Table 1). Additionally, any variation in the likelihood of past events of expansion or contraction for each species' population size ( $N$ and $N_{\mathrm{e}}$ ) may have induced differences in demographic history, speciation or divergence (Arenas, Currat, \& Excoffier, 2012; DelrieuTrottin, Maynard, \& Planes, 2014). This divergence in evolutionary history among the studied species could have also affected the genetic diversity of each trophic guild.

\subsection{Differences in levels of genetic diversity cannot be fully attributed to two commonly used traits}

We found that the level of genetic diversity genotyped by sequenced RAD tags varied across the three trophic guilds. This challenges some general assumptions about the influence of two commonly used traits on genetic diversity, that is, PLD and population size. A long PLD allowing for long-distance larval dispersal might result in more connected fish populations and thus would increase gene flow (O'Donnell et al., 2016; Selkoe \& Toonen, 2011), which may be conducive to high levels of genetic diversity. Yet, in this study, pelagic feeders displayed the longest PLD but their genetic diversity was unexpectedly the lowest of all trophic guilds (Figures 2 and 3a). This result is consistent with the claims that PLDs may be poor predictors of population structure, since larval behaviour and oceanographic features also play important roles in driving genetic diversity (Bowen, Bass, Muss, Carlin, \& Robertson, 2006; O'Donnell et al., 2016). For example, population genetic structure was shown to fluctuate by an order of magnitude within the single family of squirrelfishes, Holocentridae (Bowen et al., 2006). This probably reflects the complex relationship between PLD and genetic connectivity among lineages that diverged 50-100 million years ago (Bowen et al., 2006), a period during which Pomacentridae started to diversify as suggested by time-calibrated phylogenies (Cowman \& Bellwood, 2011; Frédérich, Sorenson, Santini, Slater, \& Alfaro, 2013). Our result may also be attributed to other parameters such as the particular physical and oceanographic settings in Moorea. The alongshore flow around the island can act as a promoter of larval dispersal or as a retention feature (Leichter et al., 2013). Larvae can also be further entrapped by another smaller scale retention system inside the lagoon (Beldade, Holbrook, Schmitt, Planes, \& Bernardi, 2016). Additionally, damselfish larvae are not passive particles as they are able to express different types of behaviour at the reef-settlement phase (Leis \& Carson-Ewart, 2002). The oceanographic features of Moorea and habitat preferences of larvae may have contributed to the lack of concordance between PLD and the level of genetic diversity in our study.

Larger local population sizes and presumably larger effective population sizes are amongst the factors that will likely increase genetic diversity (Dalongeville, Andrello, Mouillot, Albouy, \& Manel, 2016; Frankham, 2005; Hague \& Routman, 2016; Höglund, 2009). The expected genetic corollary is that species and trophic guilds with larger population sizes should display a higher genetic diversity. Surprisingly, our results reveal an opposite scenario with the lowest genetic diversity observed for the guild having the highest median population size estimated by visual census (Figures 2 and 3, Supporting Information Table S4). These results could have been due to an increased relatedness among the studied individuals, but this potential bias was ruled out by our relatedness assessment. The effective population size also depends on the number of individuals that participate to reproduction (Planes $\&$ Lenfant, 2002). A large variation in the individual reproductive 
success of pelagic feeders may have translated into differences in allelic frequencies and could have been conducive to a lower genetic diversity, albeit this hypothesis needs to be tested. Overall, variations in PLD and population size of trophic guilds do not fully elucidate the differences in levels of genetic diversity that we observed in guilds of Pomacentridae.

\subsection{Correlation between levels of genetic diversity and patterns of trophic ecology}

Before detailing our trophic data, it is important to mention that defining trophic ecology from stable isotope ratios has some limitations. Spatial (e.g., different locations or sites along the reef-scape) and temporal (e.g., distinctive seasons) variation in isotopic ratios of food sources can affect the isotopic ratios of consumers (Bearhop et al., 2004; Layman et al., 2012). These effects were minimized by collecting all fishes during a three-month field campaign in one bay and by demonstrating that the limited number of individuals caught in different reef parts (i.e., beach shore, fringing and barrier reef) and in a different bay (i.e., Haapiti) had analogous isotopic composition (Gajdzik et al., 2016). Moreover, the diet of the same fish individuals was also characterized with stomach content analysis (Gajdzik et al., 2016). This combined approach is particularly useful for omnivorous/generalized diets, which are complex to identify when only using stable isotope ratios (e.g., Caut, Angulo, \& Courchamp, 2008) because of the assimilation of a wide range of food resources with contrasting discrimination factors. Thus, while some assumptions remained in the evaluation of trophic ecology, the use of two dietary techniques that were complemented with habitat-behavioural information (Gajdzik et al., 2016) suggests that the diet and guild identification of damselfishes were robustly appraised.

Here, we provide strong evidence for a link between genetic diversity and trophic ecology as (a) clear differences emerged among trophic guilds when examining the isotopic niche width and (b) an association was found between isotopic composition and heterozygosity. Pelagic feeders occupied an isotopic niche that is, on average, 9-40 times smaller than the isotopic niche for the intermediate group and the one of benthic feeders (Figure 5c). The pelagic-feeding guild groups species that all display very narrow isotopic niches (Supporting Information Figure S6). The smaller isotopic niche size along the $\delta^{13} \mathrm{C}-\delta^{15} \mathrm{~N}$ axis (Figure $5 \mathrm{a}$ ) suggests that pelagic feeders display a smaller trophic niche width because their prey do not vary much in their isotopic compositions, i.e. copepods are the main food sources of pelagic feeders (Frédérich et al., 2009; Gajdzik et al., 2016). In addition to a small dietary breadth, the smaller isotopic niche size along the $\delta^{13} \mathrm{C}-\delta^{34} \mathrm{~S}$ axis (Figure $5 \mathrm{~b}$ ) also indicates that they forage in similar types of habitats on the reef. Pelagic feeders mostly live in areas directly bathed by the open ocean or just behind the barrier reef crest and they also behave analogously by forming shoals (Gajdzik et al., 2016). The overall small variance in isotopic niche of pelagic feeders probably results from their similar positions on the reef-scape, and their analogy in terms of dietary and behavioural requirements. Nevertheless, the stomach content-based niche of pelagic feeders was either of similar values as the dietary niches of the other two trophic guilds (Figure 4) or even higher when more individuals were added (Supporting Information Figure S4). These outcomes may be explained by the sensitivity of the TNW metric, which increases with the inclusion of more individuals that only ingested one type of food items (e.g., Bolnick et al., 2007). In other words, the great majority of pelagic-feeding individuals in our study exclusively feed on one functional type of prey (i.e., zooplankton), but some of them may ingest benthic food sources (e.g., benthic algae or eggs), suggesting some degree of dietary opportunism. The two other trophic guilds both have large isotopic and stomach-based niches (Figures 4 and 5), which implies that the range of food sources (i.e., niche along the $\delta^{13} \mathrm{C}-\delta^{15} \mathrm{~N}$ axis) and types of habitats they occupied are more diverse (i.e., niche along the $\delta^{13} \mathrm{C}-\delta^{34} \mathrm{~S}$ axis). The wide isotopic niche displayed by the benthic-feeding guild and its species' members indicate that they occupy various habitats (e.g., sand flat, dead corals or rocks), which are associated with specific feeding habits and behaviours related to habitat use (e.g., many territorial species are farming of algal lawn on corals; Hata \& Ceccarelli, 2016; Lepoint, Michel, Parmentier, \& Frédérich, 2016). In contrast, the intermediate group had the second largest isotopic niche, which is likely driven by the large diversity of prey items coming from the entire bentho-pelagic compartment (i.e., zooplankton, filamentous algae, small vagile invertebrates and benthic eggs; Frédérich, Lehanse, Vandewalle, \& Lepoint, 2010; Frédérich, Olivier, et al., 2016; Gajdzik et al., 2016). However, within this guild, species exhibited a wide variation in their isotopic niche size (Supporting Information Figure S6), which was probably due to a high degree of diet variation among individuals (e.g., Svanbäck, Quevedo, Olsson, \& Eklöv, 2015). Overall, given their ability to feed on various types of prey and/or to forage in different habitats on the reef, both the intermediate group and benthic feeders appear to have more diverse trophic attributes than pelagic feeders.

The concordance between genetic diversity and trophic ecology observed in the studied tripartite trophic guild system was also established in other organisms. A general trend towards lower genetic diversity for reduced dietary niche breadth was already found in specialist phytophagous insects, aphid Neuquenaphis spp. (Gaete-Eastman et al., 2004). Likewise, a smaller habitat range (due to fragmentation) also induced a lower genetic diversity in the ocelot (Leopardus pardalis albescens), a habitat specialist compared to the bobcat species (Lynx rufus texensis), which is considered as a habitat generalist (Janecka et al., 2016). Our result illustrating that trophic guilds affect the genetic diversity of coral reef fishes appears somewhat conflicting with mammals, for which trophic class had no effect on their genetic diversity (Doyle, Hacking, Willoughby, Sundaram, \& DeWoody, 2015). This difference may be attributed to the scale of investigation (e.g., Kelley, Farrell, \& Mitton, 2000). Here, we focused on sympatric fish populations from 13 species from a phylogenetically constrained group, whereas Doyle et al. (2015) gathered literature information from 95 mammal species from various regions. Nevertheless, by analogy with the findings on nematodes (Li et al., 2014) and felids (Janecka et al., 2016), our results revealed that the 
guild with smaller ecological amplitudes with respect to key focal resources (i.e., pelagic-feeding damselfishes) has lower levels of genetic diversity than guilds exploiting a larger array of food and habitat resources (i.e., benthic feeders and the intermediate group).

Another possible corollary for such a reduced genetic diversity is that organisms using a narrower range of resources may be more susceptible to population bottleneck, although the ecological requirements of an organism are probably not fixed but rather affected by random fluctuation of environmental resources. For example, the marginal importance of a particular resource across an organism's lifetime can vary and be context-dependent (Loxdale, Lushai, \& Harvey, 2011). A low genetic diversity in a guild and its species' members could also be linked to a shared population history, which was likely the case for the pelagic-feeding guild. Moreover, the similar trends between genetic and trophic diversity may also be a downside of the relation between morphological and foraging microhabitat specialization (e.g., Brandl, Robbins, \& Bellwood, 2015), between the diet and trophic morphology exhibited by trophic guild (Frédérich et al., 2013) or even driven by any pivotal role played by trophic guilds during the evolutionary history of Pomacentridae, but all of these hypotheses remain to be tested. Overall, as illustrated by the concept of seascape genetics (Riginos \& Liggins, 2013) and seascape ecology (Pittman, Kneib, \& Simenstad, 2011), our study suggests that differences in environmental resource use among guilds may induce genetic variation within the reef-scape.

\section{5 | CONCLUSION}

Despite the "long riddle" over the determinants of genetic diversity (e.g., life history traits, the population history or the impact of mating systems; Ellegren \& Galtier, 2016), our study strongly supports a consistency between levels of genetic diversity and patterns in trophic ecology, which represents variations in diet, trophic interactions and habitat characteristics. Often overlooked or simplified, trophic ecology appears to be linked to levels of genetic diversity while the reverse is also true. Less ecologically diverse guilds (i.e., those with more homogeneous/similar dietary and habitat characteristics), such as pelagic feeders, tend to display lower genetic diversity than guilds having broader ecological requirements (i.e., the intermediate group and benthic feeders). Our study also provides evidence that trophic guilds are not only important ecological components but also emergent genetic properties within the community.

Several questions emerged from our study and need to be addressed in the future. At an evolutionary timescale, the link between phylogeny and genetic diversity must be investigated especially in organisms whose diversification consisted of convergent evolution across similar morphology (e.g., Pomacentridae, Anolis lizards). The genetic architecture behind these phenomena of convergences should be resolved to better understand the importance of ecological opportunity and genetic constraints in controlling the dynamics of these events of adaptive radiation. At an ecological timescale, future studies should strive to appraise more precisely the mechanisms underlying trophic ecology and genetic diversity patterns (e.g., the relative importance of larval vs. adult ecology on levels of genetic diversity) and to include additional data on the phenotype of each genotype to draw accurate predictions. We recommend expanding this investigation not only to other coral reef fish families but more broadly to other taxa as well.

\section{ACKNOWLEDGEMENTS}

This research was supported by a grant from F.R.S-FNRS (contract no. 24880335), a grant from the Belgium-U.S. FULBRIGHT commission (no. 15151491), and a subvention from the "Concours de bourse de voyage 2014" of the Wallonia-Brussels Federation and were all attributed to L.G. We thank the research station CRIOBE (Moorea, French Polynesia) for providing hospitality, laboratory facilities and help in the field. We are also grateful to the five anonymous reviewers, Dr. Loïc Michel and Dr. Nicolas Sturaro for their valuable comments on earlier versions of this paper.

\section{AUTHOR CONTRIBUTIONS}

L.G. and B.F. designed the experiment; L.G. and B.F. collected the data; L.G. processed the samples for stable isotope analysis with the help of G.L.; L.G. performed the molecular work and statistical analyses with the help of G.B.; L.G. drafted the manuscript with substantial contributions of all authors who approved the final version.

\section{DATA ACCESSIBILITY}

The damselfish isotopic data set and the values of food sources used here are given in the online supporting information (Tables S2 and S3). Parts of this isotopic data set were already archived in the Dryad Digital Repository: https://doi.org/10.5061/dryad.pj784 (Gajdzik et al., 2018b). All Fastq sequence files are available from the GenBank at the National Center for Biotechnology Information short-read archive database (accession number PRJNA496400). Associated metadata are also available at GeOMe (GUID https:// n2t.net/ark:/21,547/BdE2). The R script "si_div" is made available by Cucherousset \& Villéger in the supplementary data (http://www.sciencedirect.com/science/article/pii/S1470160X15001569) and SIAR index by Andrew Jackson (cran.r - project.org/web/packages/siar/ siar.pdf).

\section{ORCID}

Laura Gajdzik (iD https://orcid.org/0000-0001-6781-9625

\section{REFERENCES}

Arenas, M., Currat, R. N., \& Excoffier, L. (2012). Consequences of range contractions and range shifts on molecular diversity. Molecular Biology and Evolution, 29, 207-2018. https://doi.org/10.1093/ molbev/msr187

Baird, N. A., Etter, P. D., Atwood, T. S., Currey, M. C., Shiver, A. L., Lewis, Z. A., ... Johnson, E. A. (2008). Rapid SNP discovery and genetic 
mapping using sequenced RAD markers. PLoS One, 3, 1-7. https:// doi.org/10.1371/journal.pone.0003376

Bazin, E., Glémin, S., \& Galtier, N. (2006). Population size does not influence mitochondrial genetic diversity in animals. Science, 312, 570572. https://doi.org/10.1126/science.1122033

Bearhop, S., Adams, C. E., Waldron, S., Fuller, R. A., \& Macleod, H. (2004). Determining trophic niche width: A novel approach using stable isotope analysis. Journal of Animal Ecology, 73, 1007-1012.

Beldade, R., Holbrook, S. J., Schmitt, R. J., Planes, S., \& Bernardi, G. (2016). Spatial patterns of self-recruitment of a coral reef fish in relation to island-scale retention mechanisms. Molecular Ecology, 25, 5203-5211. https://doi.org/10.1111/mec.13823

Blondel, J. (2003). Guilds or functional groups: Does it matter? Oikos, 100, 223-231. https://doi.org/10.1034/j.1600-0706.2003.12152.x

Bolnick, D. I., Svanbäck, R., Araújo, M. S., \& Persson, L. (2007). Comparative support for the niche variation hypothesis that more generalized populations also are more heterogeneous. Proceedings of the National Academy of Sciences of the United States of America, 104, 10075-10079. https://doi.org/10.1073/pnas.0703743104

Bolnick, D. I., Yang, L. H., Fordyce, J. A., Davis, J. M., \& Svanbäck, R. (2002). Measuring individual-level resource specialization. Ecology, 83, 29362941. https://doi.org/10.1890/0012-9658(2002)083[2936:MILRS]2 $.0 . \mathrm{CO} ; 2$

Bonjean, F., \& Lagerloef, G. S. E. (2002). Diagnostic model and analysis of the surface currents in the tropical Pacific Ocean. Journal of Physical Oceanography, 2938-2954. https://doi. org/10.1175/1520-0485(2002)032<2938:DMAAOT>2.0.CO;2

Bowen, B. W., Bass, A. L., Muss, A., Carlin, J., \& Robertson, D. R. (2006). Phylogeography of two Atlantic squirrelfishes (Family Holocentridae): Exploring links between pelagic larval duration and population connectivity. Marine Biology, 149, 899-913. https://doi.org/10.1007/ s00227-006-0252-1

Boyero, L., Pearson, R. G., Dudgeon, D., Graça, M. A. S., Gessner, M. O., Albariño, R. J., ... Pringle, C. M. (2011). Global distribution of a key trophic guild contrasts with common latitudinal diversity patterns. Ecology, 92, 1839-1848. https://doi.org/10.1890/10-2244.1

Brandl, S. J., Robbins, W. D., \& Bellwood, D. R. (2015). Exploring the nature of ecological specialization in a coral reef fish community: Morphology, diet and foraging microhabitat use. Proceedings of the Royal Society of London B: Biological Sciences, 282, 20151147. https:// doi.org/10.1098/rspb.2015.1147

Briggs, J. C., \& Bowen, B. W. (2012). A realignment of marine biogeographic provinces with particular reference to fish distributions. Journal of Biogeography, 39, 12-30. https://doi. org/10.1111/j.1365-2699.2011.02613.x

Brooks, A. (2016). MCR LTER: Coral Reef: Long-term Population and Community Dynamics: Fishes, ongoing since 2005.

Brumfield, R. T., Beerli, P., Nickerson, D. A., \& Edwards, S. V. (2003). The utility of single nucleotide polymorphisms in inferences of population history. Trends in Ecology and Evolution, 18, 249-256. https://doi. org/10.1016/S0169-5347(03)00018-1

Catchen, J. M., Amores, A., Hohenlohe, P. A., Cresko, W. A., \& Postlethwait, J. H. (2011). Stacks: Building and genotyping loci de novo from shortread sequences. G3: Genes Genomes Genetics, 1, 171-182.

Catchen, J. M., Hohenlohe, P. A., Bassham, S., Amores, A., \& Cresko, W. A. (2013). Stacks: An analysis tool set for population genomics. Molecular Ecology, 22, 3124-3140. https://doi.org/10.1111/ mec.12354

Caut, S., Angulo, E., \& Courchamp, F. (2008). Caution on isotopic model use for analyses of consumer diet. Canadian Journal of Zoology, 86, 438-445. https://doi.org/10.1139/Z08-012

Clarke, M. R. B. (1980). The reduced major axis of a bivariate sample. Biometrika, 67, 441-446. https://doi.org/10.1093/biomet/67.2.441

Coplen, T. B. (2011). Guidelines and recommended terms for expression of stable-isotope-ratio and gas-ratio measurement results. Rapid
Communications in Mass Spectrometry, 25, 2538-2560. https://doi. org/10.1002/rcm.5129

Cowman, P. F., \& Bellwood, D. R. (2011). Coral reefs as drivers of cladogenesis: Expanding coral reefs, cryptic extinction events, and the development of biodiversity hotspots. Journal of Evolutionary Biology, 24, 2543-2562. https://doi.org/10.1111/j.1420-9101.2011.02391.x

Cucherousset, J., \& Villéger, S. (2015). Quantifying the multiple facets of isotopic diversity: New metrics for stable isotope ecology. Ecological Indicators, 56, 152-160. https://doi.org/10.1016/j. ecolind.2015.03.032

Dalongeville, A., Andrello, M., Mouillot, D., Albouy, C., \& Manel, S. (2016). Ecological traits shape genetic diversity patterns across the Mediterranean Sea: A quantitative review on fishes. Journal of Biogeography, 43, 845-857. https://doi.org/10.1111/jbi.12669

Davis, J. (1986). Statistics and data analysis in geology. [Hoboken, NJ: John Wiley \& Sons.

Delrieu-Trottin, E., Maynard, J., \& Planes, S. (2014). Endemic and widespread coral reef fishes have similar mitochondrial genetic diversity. Proceedings of the Royal Society of London B: Biological Sciences, 281, 20141068.

Doyle, J. M., Hacking, C. C., Willoughby, J. R., Sundaram, M., \& DeWoody, J. A. (2015). Mammalian genetic diversity as a function of habitat, body size, trophic class, and conservation status. Journal of Mammalogy, 96, 564-572. https://doi.org/10.1093/jmammal/ gyv061

Dray, S., Dufour, A. B., \& Chessel, D. (2007). The ade4 package-II: Twotable and K-table methods. $R$ News, 7, 47-52.

Ellegren, H., \& Galtier, N. (2016). Determinants of genetic diversity. Nature Reviews Genetics, 17, 422-433. https://doi.org/10.1038/ nrg.2016.58

Elliott, M., Whitfield, A. K., Potter, I. C., Blaber, S. J. M., Cyrus, D. P., Nordlie, F. G., \& Harrison, T. D. (2007). The guild approach to categorizing estuarine fish assemblages: A global review. Fish and Fisheries, 8, 241-268. https://doi.org/10.1111/j.1467-2679.2007. 00253.x

Engels, W. R. (2009). Exact tests for Hardy-Weinberg proportions. Genetics, 183, 1431-1441. https://doi.org/10.1534/ genetics.109.108977

Excoffier, L., \& Lischer, H. E. L. (2010). Arlequin suite ver 3.5: A new series of programs to perform population genetics analyses under Linux and Windows. Molecular Ecology Resources, 10, 564-567. https://doi. org/10.1111/j.1755-0998.2010.02847.x

Fauvelot, C., Lemaire, C., Planes, S., \& Bonhomme, F. (2007). Inferring gene flow in coral reef fishes from different molecular markers: Which loci to trust? Heredity, 99, 331-339. https://doi.org/10.1038/ sj.hdy. 6801005

Fisher, R. A. (1930). The genetical theory of natural selection. Oxford, UK: Oxford University Press.

Frankham, R. (2005). Genetics and extinction. Biological Conservation, 126, 131-140. https://doi.org/10.1016/j.biocon.2005.05.002

Frédérich, B., Cooper, W. J., \& Aguilar-Medrano, R. (2016). Ecomorphology and iterative ecological radiation of damselfishes. In B. Frédérich, \& E. Parmentier (Eds.), Biology of damselfishes (pp. 183-203). Boca Raton, FL: CRC Press.

Frédérich, B., Fabri, G., Lepoint, G., Vandewalle, P., \& Parmentier, E. (2009). Trophic niches of thirteen damselfishes (Pomacentridae) at the Grand Récif of Toliara, Madagascar. Ichthyological Research, 56, 10-17. https://doi.org/10.1007/s10228-008-0053-2

Frédérich, B., Lehanse, O., Vandewalle, P., \& Lepoint, G. (2010). Trophic niche width, shift, and specialization of Dascyllus aruanus in Toliara lagoon, Madagascar. Copeia, 2, 218-226. https://doi.org/10.1643/ CE-09-031

Frédérich, B., Olivier, D., Gajdzik, L., \& Parmentier, E. (2016). Trophic ecology of damselfishes. In B. Frédérich, \& E. Parmentier (Eds.), Biology of damselfishes (pp. 153-167). Boca Raton, FL: CRC Press. 
Frédérich, B., \& Parmentier, E. (Eds.) (2016) Biology of damselfishes. Boca Raton, FL: CRC Press.

Frédérich, B., Sorenson, L., Santini, F., Slater, G. J., \& Alfaro, M. E. (2013). Iterative ecological radiation and convergence during the evolutionary history of damselfishes (Pomacentridae). The American Naturalist, 181, 94-113. https://doi.org/10.1086/668599

Fricke, R., Eschmeyer, W. N., \& van der Laan, R. (Eds). (2018). Catalog of fishes: genera, species, references. Retrieved from http://researcharchive.calacademy.org/research/ichthyology/catalog/fishcatmain.asp. (accessed 16 October 2018).

Froese, R., \& Pauly, D. (2016). FishBase. World Wide Web electronic publication. Retrieved from www.fishbase.org. Accessed November 2016

Fry, B. (2002). Stable isotopic indicators of habitat use by Mississippi River fish. Journal of the North American Benthological Society, 21, 676-685. https://doi.org/10.2307/1468438

Gaete-Eastman, C., Figueroa, C. C., Olivares-Donoso, R., Niemeyer, H. M., \& Ramírez, C. C. (2004). Diet breadth and its relationship with genetic diversity and differentiation: The case of southern beech aphids (Hemiptera: Aphididae). Bulletin of Entomological Research, 94, 219-227. https://doi.org/10.1079/BER2004298

Gaither, M. R., Toonen, R. J., Robertson, D. R., Planes, S., \& Bowen, B. W. (2010). Genetic evaluation of marine biogeographical barriers: Perspectives from two widespread Indo-Pacific snappers (Lutjanus kasmira and Lutjanus fulvus). Journal of Biogeography, 37, 133-147. https://doi.org/10.1111/j.1365-2699.2009.02188.x

Gaither, M. R., Bowen, B. W., Bordenave, T.-R., Rocha, L. A., Newman, S. J., Gomez, J. A., ... Craig, M. T. (2011). Phylogeography of the reef fish Cephalopholis argus (Epinephelidae) indicates Pleistocene isolation across the Indo-Pacific barrier with contemporary overlap in the coral triangle. BMC Evolutionary Biology, 11, 189. https://doi. org/10.1186/1471-2148-11-189

Gajdzik, L., Parmentier, E., Michel, L. N., Soong, K., Lepoint, G., \& Frédérich, B. (2018a). Similar levels of trophic and functional diversity within damselfish assemblages across Indo-Pacific coral reefs. Functional Ecology, 32, 1358-1369.

Gajdzik, L., Parmentier, E., Michel, L. N., Soong, K., Lepoint, G., \& Frédérich, B. (2018b). Similar levels of trophic and functional diversity within damselfish assemblages across Indo-Pacific coral reefs. Dryad Digital Repository, https://doi.org/10.5061/dryad.pj784

Gajdzik, L., Parmentier, E., Sturaro, N., \& Frédérich, B. (2016). Trophic specializations of damselfishes are tightly associated with reef habitats and social behaviours. Marine Biology, 163, 1-15. https://doi. org/10.1007/s00227-016-3020-x

Gruber, B., Unmack, P. J., Berry, O. F., \& Georges, A. (2018). DARTR: An $R$ package to facilitate analysis of SNP data generated from reduced representation genome sequencing. Molecular Ecology Resources, 18, 691-699.

Habel, K., Grasman, R., Gramacy, R. B., Stahel, A., \& Sterratt, D. C. (2015). geometry: Mesh Generation and Surface Tesselation. R package version 0.3-6.

Hague, M. T. J., \& Routman, E. J. (2016). Does population size affect genetic diversity? A test with sympatric lizard species. Heredity, 116, 92-98. https://doi.org/10.1038/hdy.2015.76

Hammer, Ø., Harper, D. A. T., \& Ryan, P. D. (2001). PAST: paleontological statistics software package for education and data analysis. Palaeontologia Electronica, 4, 9 pp.

Hata, H., \& Ceccarelli, D. M. (2016). Farming behaviour of territorial damselfishes. In E. Parmentier, \& B. Frédérich (Eds.), Biology of damselfishes (pp. 122-152). Boca Raton, FL: CRC Press.

Helfman, G., Collette, B. B., Facey, D. E., \& Bowen, B. W. (2009). The diversity of fishes: Biology, evolution, and ecology. Hoboken, NJ: John Wiley \& Sons.

Höglund, J. (2009). Evolutionary conservation genetics. Oxford, UK: Oxford University Press.
Hughes, A. R., Inouye, B. D., Johnson, M. T., Underwood, N., \& Vellend, M. (2008). Ecological consequences of genetic diversity. Ecology Letters, 11, 609-623. https://doi.org/10.1111/j.1461-0248.2008.01179.x

Hyslop, E. J. (1980). Stomach contents analysis-a review of methods and their application. Journal of Fish Biology, 17, 411-429. https://doi. org/10.1111/j.1095-8649.1980.tb02775.x

Janecka, J. E., Tewes, M. E., Davis, I. A., Haines, A. M., Caso, A., \& Blankemship, T. L. (2016). Genetic differences in the response to landscape fragmentation by a habitat generalist, the bobcat, and a habitat specialist, the ocelot. Conservation Genetics, 17, 1093-1108. https://doi.org/10.1007/s10592-016-0846-1

Johnson, M. T. J., \& Agrawal, A. A. (2005). Plant genotype and environment interact to shape a diverse arthropod community on evening primrose (Oenothera biennis). Ecology, 86, 874-885. https://doi. org/10.1890/04-1068

Jombart, T., \& Ismaïl, A. (2011). adegenet 1.3-1: New tools for the analysis of genome-wide SNP data. Bioinformatics, 27, 3070-3071. https:// doi.org/10.1093/bioinformatics/btr521

Jones, T. S., Allan, E., Härri, S. A., Krauss, J., Müller, C. B., \& Van Veen, F. J. F. (2011). Effects of genetic diversity of grass on insect species diversity at higher trophic levels are not due to cascading diversity effects. Oikos, 120, 1031-1036. https://doi. org/10.1111/j.1600-0706.2010.18957.x

Kelley, S. T., Farrell, B. D., \& Mitton, J. B. (2000). Effects of specialization on genetic differentiation in sister species of bark beetles. Heredity, 84, 218-227. https://doi.org/10.1046/j.1365-2540.2000.00662.x

Kuo, S., \& Shao, K. (1991). Feeding habits of damselfishes (Pomacentridae) from the southern part of Taiwan. Journal of the Fisheries Society of Taiwan, 18, 165-176.

Layman, C. A., Araujo, M. S., Boucek, R., Hammerschlag-Peyer, C. M., Harrison, E., Jud, Z. R., ... Bearhop, S. (2012). Applying stable isotopes to examine food-web structure: An overview of analytical tools. Biological Reviews of the Cambridge Philosophical Society, 87, 545-562. https://doi.org/10.1111/j.1469-185X.2011.00208.x

Leichter, J. J., Alldredge, A. L., Bernardi, G., Brooks, A. J., Carlson, C. A., Carpenter, R. C., ... Wyatt, A. S. J. (2013). Biological and physical interactions on a tropical island coral reef: Transport and retention processes on Moorea, French Polynesia. Oceanography, 26, 52-63. https://doi.org/10.5670/oceanog.2013.45

Leis, J. M. (1991). The pelagic stage of reef fishes. In P. Sale (Ed.), The ecology of fishes on coral reefs (pp. 182-229). San Diego, CA: Academic Press Inc.

Leis, J. M., \& Carson-Ewart, B. M. (2002). In situ settlement behaviour of damselfish (Pomacentridae) larvae. Journal of Fish Biology, 61, 325346. https://doi.org/10.1111/j.1095-8649.2002.tb01569.x

Lepoint, G., Michel, L. N., Parmentier, E., \& Frédérich, B. (2016). Trophic ecology of the seagrass-inhabiting footballer demoiselle Chrysiptera annulata (Peters, 1855); comparison with three other reef-associated damselfishes. Belgian Journal of Zoology, 146, 21-32.

Li, S., Jovelin, R., Yoshiga, T., Tanaka, R., \& Cutter, A. D. (2014). Specialist versus generalist life histories and nucleotide diversity in Caenorhabditis nematodes. Proceedings of the Royal Society of London B: Biological Sciences, 281, 20132858.

Lischer, H. E. L., \& Excoffier, L. (2012). PGDSpider: An automated data conversion tool for connecting population genetics and genomics programs. Bioinformatics, 28, 298-299. https://doi.org/10.1093/ bioinformatics/btr642

Liu, S.-Y.- V., Chang, F.-T., Borsa, P., Chen, W.-J., \& Dai, C.-F. (2014). Phylogeography of the humbug damselfish, Dascyllus aruanus (Linnaeus, 1758): Evidence of Indo-Pacific vicariance and genetic differentiation of peripheral populations. Biological Journal of the Linnean Society, 113, 931-942.

Loiselle, B. A., Sork, V. L., Nason, J., \& Graham, C. (1995). Spatial genetic structure of a tropical understory shrub, Psychotria officinalis (Rubiaceae). American Journal of Botany, 82, 1420-1425. 
Longo, G., \& Bernardi, G. (2015). The evolutionary history of the embiotocid surfperch radiation based on genome-wide RAD sequence data. Molecular Phylogenetics and Evolution, 88, 55-63. https://doi. org/10.1016/j.ympev.2015.03.027

Loxdale, H. D., Lushai, G., \& Harvey, J. A. (2011). The evolutionary improbability of "generalism" in nature, with special reference to insects. Biological Journal of the Linnean Society, 103, 1. https://doi. org/10.1111/j.1095-8312.2011.01627.x

Meirmans, P. G., \& Van Tienderen, P. (2004). Genotype and genodive: Two programs for the analysis of genetic diversity of asexual organisms. Molecular Ecology Notes, 4, 792-794. https://doi. org/10.1111/j.1471-8286.2004.00770.x

Messmer, V., Jones, G. P., Munday, P. L., \& Planes, S. (2012). Concordance between genetic and species diversity across the Pacific Ocean biodiversity gradient. Evolution, 66, 3902-3917.

Miller, M. R., Dunham, J. P., Amores, A., Cresko, W. A., \& Johnson, E. A. (2007). Rapid and cost-effective polymorphism identification and genotyping using restriction site associated DNA (RAD) markers. Genome Research, 17, 240-248. https://doi.org/10.1101/gr.5681207

Miller, M. R., Brunelli, J. P., Wheeler, P. A., Liu, S., Rexroad, C. R., Plati, Y., ... Thorgaard, G. H. (2012). A conserved haplotype controls parallel adaptation in geographically distant salmonid populations. Molecular Ecology, 21, 237-249. https://doi. org/10.1111/j.1365-294X.2011.05305.x

Newsome, S. D., Martinez del Rio, C., Bearhop, S., \& Phillips, D. L. (2007). A niche for isotopic ecology. Frontiers in Ecology and the Environment, 5, 429-436. https://doi.org/10.1890/1540-9295(20 07)5[429:ANFIE]2.0.CO;2

O'Donnell, J. L., Beldade, R., Mills, S. C., Williams, H. E., \& Bernardi, G. (2016). Life history, larval dispersal, and connectivity in coral reef fish among the Scattered Islands of the Mozambique Channel. Coral Reefs, 36, 223-232.

Ovenden, J. R., Leigh, G. M., Blower, D. C., Jones, A. T., Moore, A., Bustamante, C., ... Dudgeon, C. L. (2016). Can estimates of genetic effective population size contribute to fisheries stock assessments? Journal of Fish Biology, 89, 2505-2518. https://doi.org/10.1111/jfb.13129

Paradis, E., Claude, J., \& Strimmer, K. (2004). APE: Analyses of phylogenetics and evolution in R language. Bioinformatics, 20, 289-290.

Pittman, S. J., Kneib, R. T., \& Simenstad, C. A. (2011). Practicing coastal seascape ecology. Marine Ecology Progress Series, 427, 187-190. https://doi.org/10.3354/meps09139

Planes, S., Doherty, P. J., \& Bernardi, G. (2001). Strong genetic divergence among populations of a marine fish with limited dispersal, Acanthochromis polyacanthus, within the Great Barrier reef and the Coral Sea. Evolution, 55, 2263-2273. https://doi. org/10.1111/j.0014-3820.2001.tb00741.x

Planes, S., \& Lenfant, P. (2002). Temporal change in the genetic structure between and within cohorts of a marine fish, Diplodus sargus, induced by a large variance in individual reproductive success. Molecular Ecology, 11, 1515-1524. https://doi.org/10.1046/j.1365-294X.2002.01521.x

R Core Team (2011). R: A language and environment for statistical computing. Vienna, Austria: R Foundation for Statistical Computing.

Riginos, C., \& Liggins, L. (2013). Seascape genetics: Populations, individuals, and genes marooned and adrift. Geography Compass, 7, 197-216. https://doi.org/10.1111/gec3.12032

Rigolet, C., Thiébaut, E., Brind'Amour, A., \& Dubois, S. F. (2015). Investigating isotopic functional indices to reveal changes in the structure and functioning of benthic communities. Functional Ecology, 29, 1350-1360. https://doi.org/10.1111/1365-2435.12444

Root, R. B. (1967). The niche exploitation pattern of the blue-gray gnatcatcher. Ecological Monographs, 37, 317-350. https://doi. org/10.2307/1942327
Roughgarden, J. (1974). Niche width, biogeographic patterns among Anolis lizard populations. The American Naturalist, 108, 683-718. https://doi.org/10.1086/282924

Rousset, F. (2008). genepop'007: A complete re-implementation of the genepop software for Windows and Linux. Molecular Ecology Resources, 8, 103-106. https://doi.org/10.1111/j.1471-8286.2007.01931.x

Selkoe, K. A., Gaggiotti, O. E., Treml, E. A., Wren, J. L. K., Donovan, M. K., Connectivity, H. R., \& consortium, \& Toonen, R. J., (2016). The DNA of coral reef biodiversity: Predicting and protecting genetic diversity of reef assemblages. Proceedings of the Royal Society of London B: Biological Sciences, 283, 20160354.

Selkoe, K. A., \& Toonen, J. (2011). Marine connectivity: A new look at pelagic larval duration and genetic metrics of dispersal. Marine Ecology Progress Series, 436, 291-305. https://doi.org/10.3354/meps09238

Soulé, M. E. (1987). Viable populations for conservation. Cambridge, UK: Cambridge University Press.

Svanbäck, R., Quevedo, M., Olsson, J., \& Eklöv, E. (2015). Individuals in food webs: The relationships between trophic position, omnivory and among-individual diet variation. Oecologia, 178, 103-114. https://doi. org/10.1007/s00442-014-3203-4

Tajima, F. (1983). Evolutionary relationship of DNA sequences in finite populations. Genetics, 105, 437-460.

Thresher, R. E., Colin, P. L., \& Bell, L. J. (1989). Planktonic duration, distribution and population structure of western and central Pacific damselfishes (Pomacentridae). Copeia, 420-434. https://doi. org/10.2307/1445439

Underwood, J. N., Travers, M. J., \& Gilmour, J. P. (2012). Subtle genetic structure reveals restricted connectivity among populations of a coral reef fish inhabiting remote atolls. Ecology and Evolution, 2, 666679. https://doi.org/10.1002/ece3.80

Wellington, G. M., \& Victor, B. C. (1989). Planktonic larval duration of one hundred species of Pacific and Atlantic damselfishes (Pomacentridae). Marine Biology, 101, 557-567. https://doi.org/10.1007/BF00541659

Wyatt, A. S. J., Waite, A. M., \& Humphries, S. (2012). Stable isotope analysis reveals community-level variation in fish trophodynamics across a fringing coral reef. Coral Reefs, 31, 1029-1044. https://doi. org/10.1007/s00338-012-0923-y

Zaccarelli, N., Bolnick, D. I., \& Mancinelli, G. (2013). RInSp: An r package for the analysis of individual specialization in resource use. Methods in Ecology and Evolution, 4, 1018-1023.

Zhang, B.-D., Xue, D.-X., Wang, J., Li, Y.-L., Liu, B.-J., \& Liu, J.-X. (2016). Development and preliminary evaluation of a genomewide single nucleotide polymorphisms resource generated by RAD-seq for the small yellow croaker (Larimichthys polyactis). Molecular Ecology Resources, 16, 755-768. https://doi.org/10.1111/1755-0998.12476

\section{SUPPORTING INFORMATION}

Additional supporting information may be found online in the Supporting Information section at the end of the article.

How to cite this article: Gajdzik L, Bernardi G, Lepoint G, Frédérich B. Genetic diversity mirrors trophic ecology in coral reef fish feeding guilds. Mol Ecol. 2018;27:5004-5018. https:// doi.org/10.1111/mec.14936 